\title{
La geopolítica de la austeridad europea: Ordnungspolitik y la sombra del modelo económico alemán sobre la crisis de la Eurozona*
}

\author{
John AGNEW \\ Department of Geography \\ University of California Los Angeles \\ jagnew@geog.ucla.edu
}

Recibido: 26-06-2015

Aceptado: 05-09-2015

\section{RESUMEN}

Dos historias sobre la crisis de la Eurozona han dominado los relatos académicos y populares en los últimos cinco años: 1) virtuosos países del norte de Europa frente a los derrochadores del sur, y 2) una mera extensión de la crisis bancaria de los años 2008-9 en el mercado de bonos de la Eurozona. Este artículo propone que la crisis económica es realmente una crisis geopolítica, que refleja la discordancia entre el modelo normativo de la Eurozona basado en la ideología alemana y la realidad de la heterogeneidad económica de la Eurozona.

Palabras clave: paradigma de política; austeridad; Eurozona; Ordnungspolitik; Alemania.

\section{The Geopolitics of European Austerity: Ordnungspolitik and the German Economic Model's Shadow over the Eurozone Crisis}

\begin{abstract}
Over the past five years two stories about the Eurozone crisis have dominated popular and academic accounts: (1) virtuous northern countries versus profligate southern ones and (2) a simple extension of the 2008-9 banking crisis into the Eurozone bond market. This paper proposes that the economic crisis is really a geopolitical one reflecting the mismatch between the normative model for the Eurozone based on German ideology and the reality of the Eurozone's economic heterogeneity.
\end{abstract}

Key words: policy paradigm; austerity; Eurozone; Ordnungspolitik; Germany.

* Traducido del original en inglés por Marina Díaz Sanz. 


\title{
A geopolítica da austeridade europeia: Ordnungspolitik e a sombra do modelo do modelo econômico alemão sobre a crise da Eurozona
}

\begin{abstract}
RESUMO
Duas histórias sobre a crise da Eurozona têm dominado os relatos acadêmicos e populares nos últimos cinco anos: 1) virtuosos países do norte da Europa diante dos esbanjadores do sul; 2) uma mera extensão da crise bancária dos anos 2008-9 no mercado de bônus da Eurozona. Este artigo propõe que a crise econômica é realmente uma crise geopolítica, que reflete a discordância entre o modelo normativo da Eurozona baseado na ideologia alemã e a realidade da heterogeneidade econômica da Eurozona.
\end{abstract}

Palavras-chave: paradigma de política; austeridade; Eurozona; Ordnungspolitik; Alemanha.

\section{REFERENCIA NORMALIZADA}

Agnew, John (2015) "La geopolítica de la austeridad europea: Ordnungspolitik y la sombra del modelo económico alemán sobre la crisis de la Eurozona". Geopolítica(s). Revista de estudios sobre espacio y poder, vol. 6, núm. 2, 179-200.

SUMARIO: 1. Relatos populares sobre la crisis de la Eurozona. 2. Analizando la crisis de la Eurozona. 3. ¿Qué es la Ordnungspolitik? 4. Los límites de la Ordnungspolitik en el capitalismo heterogéneo. 5. La tesis sobre el desajuste territorial y la crisis de la Eurozona. Conclusión. Bibliografía.

En los medios de comunicación europeos y entre los economistas de distintas tendencias políticas son recurrentes dos historias sobre la crisis que está arruinando las economías periféricas de la Eurozona (Portugal, Irlanda, Italia, Grecia y España) desde hace cinco años. La más popular sin duda es que estamos en el momento cumbre del inevitable choque entre los virtuosos del norte - especialmente, Alemania, Finlandia y Holanda- y los derrochadores del sur (más Irlanda), embarcados todos ellos lamentablemente por ahora en un único sistema monetario que desde 1999 trata de "profundizar" el proyecto político de integración europea. En este sentido, las políticas de austeridad han resultado ser necesarias para afrontar la profunda deuda pública provocada por la "apuesta" en favor del gasto público y la inadecuada recaudación de impuestos en los países derrochadores. Final e inevitablemente la economía ha triunfado sobre la política. La segunda también es de naturaleza economicista pero vislumbra la crisis de la Eurozona simplemente como la extensión de la crisis bancaria anterior (2008-9) en los mercados de deuda de los miembros de la Eurozona. Así, los países periféricos, con unas economías públicas más débiles, están pagando en mayor medida las malas apuestas de los banqueros que produjeron la crisis de la banca. Una versión de este argumento es que la situación actual puede achacarse sin más a la tendencia general del capitalismo hacia las crisis. Una crisis es simplemente el germen de la próxima y así hasta el infinito. Esto suena, por decirlo de alguna, bastante vago. La visión más ortodoxa remite al 
mal diseño de la Eurozona desde el principio, donde rige la separación entre la política monetaria a nivel de la Eurozona y la política fiscal, en manos de los gobiernos de los Estados miembros. Lo que resulta "obvio" para todo el mundo es la forma geopolítica de esta crisis basada en un conflicto directo entre un centro geográfico que es económicamente más fuerte y una periferia evidentemente más débil. La segunda historia al menos establece alguna conexión con el rescate público del sistema financiero al principio de la crisis. La primera pasa esto por alto completamente e identifica como culpables de la crisis al despilfarro en los programas de bienestar, las pensiones, etc., además de la evasión fiscal. Al margen de la verdad empírica de esto último como factor explicativo de la falta de competitividad en las economías nacionales, la falta de conexión entre la crisis de la Eurozona y el colapso del sistema bancario trasluce una agenda ideológica anti-bienestar que tiene poco o nada que ver con entender el carácter de la crisis actual en sí mismo. Los casos de Reino Unido o los Estados de Kansas o Wisconsin, donde la crisis financiera ha sido un claro pretexto para recortar el gasto en bienes públicos, apuntan en esta dirección.

Sin embargo, la crisis de deuda que aqueja a la Eurozona desde que en 2008 estallara la crisis financiera global no es simplemente el resultado del desequilibrio absoluto de la deuda entre economías nacionales más o menos fuertes, donde las últimas están heridas de muerte por los rescates de los gobiernos a bancos insolventes en una escala mucho mayor que en las primeras. Se trata, por encima de todo, de una crisis geopolítica que refleja la falta de concordancia entre el modelo normativo de una economía nacional "exitosa" basada, en buena medida, en la experiencia alemana por la cual el modelo de una economía más pequeña y orientada a la exportación se proyecta sobre la economía de una Eurozona heterogénea. En otras palabras, es una crisis geopolítica en curso basada en el conflicto práctico entre las demandas políticas de una concepción de política económica alemana históricamente institucionalizada (Ordnungspolitik o "políticas de ordenación") que ha llegado a dominar la política monetaria de la Eurozona, por una parte; y el hecho de que, por otra parte, en sus orígenes, la crisis es una crisis económico-política de la forma territorial (la economía nacional) que toma la experiencia alemana de política económica. Esta crisis es el resultado del hecho de que la economía global desde la que emerge la crisis financiera funciona de acuerdo a prácticas capitalistas neoliberales que entran en contradicción con el modelo alemán incluido, y de forma creciente, dentro de la propia Alemania. Si simplemente el modelo alemán no puede de repente reemplazar las más diversas economías políticas de la Eurozona, su propia localización dentro de un "capitalismo heterogéneo" (Jessop, 2012) convierte su aplicación como estándar de excelencia en las economías periféricas en un absoluto anacronismo. La expectativa por parte de los líderes políticos alemanes con el apoyo de la Unión Europea y los líderes del FMI de que la aplicación de un modelo alemán idealizado puede, por arte de magia, reformar las economías públicas fuer- 
temente endeudadas como la de Grecia ha sido el factor principal de la persistencia y la profundización de la crisis en la Eurozona entre los años 2010 y 2015.

Este artículo realiza, en primer lugar, un breve repaso de las dos visiones dominantes sobre la crisis. A continuación la atención se centra en el recorrido práctico de la crisis y el papel de la perspectiva alemana sobre la economía política en su perpetuación, especialmente en relación con el caso de Grecia. El artículo presenta la línea argumental de la historia de la Ordnungspolitik alemana y sus límites como perspectiva de política económica hoy en día tanto dentro como fuera de sus fronteras. Finalmente, la tesis sobre la falta de concordancia a nivel territorial sugiere que el reconocimiento público y amplio sobre los límites territoriales de la aplicación del modelo político alemán idealizado es necesario para el futuro de la Eurozona y, por lo tanto, para que la Unión Europea avance hacia la resolución de la crisis de la Eurozona en particular y profundizar en la posibilidad de la integración europea a largo plazo de forma más general. No obstante, tal y como están las cosas a mediados del año 2015 ninguna de la dos posibilidades parece muy probable.

\section{Relatos populares sobre la crisis de la Eurozona}

En la mayor parte de los discursos populares contemporáneos la crisis de la Eurozona se presenta como todo menos como un conflicto entre visiones políticas institucionalizadas concretas y prácticas gubernamentales. Se presenta normalmente como, o bien el resultado del despilfarro gubernamental y/o las débiles economías de países fuertemente endeudados o, paralelamente, como el resultado de modalidades de concesión de préstamos para encubrir la deuda bancaria intrínseca al capitalismo neoliberal que se encuentra en la raíz de las finanzas globalizadas que provocaron la crisis financiera en 2008. En esta sección, utilizo descripciones amplias de estas perspectivas basadas en una serie de fuentes académicas y representaciones mediáticas de la crisis de la Eurozona. En el primer caso, hay una tendencia a subrayar estereotipos sobre los comportamientos nacionales que se retrotraen a desaires históricos y resentimientos albergados desde mucho antes del comienzo de la crisis. En el segundo caso, la crisis se "naturaliza" como un producto derivado de las maquinaciones del capital que ejerce su anclaje espacial en los eslabones más débiles de la gran cadena de acumulación capitalista o el pobre diseño institucional de la Eurozona que concentraba sus efectivos negativos en economías ya débiles desde un punto de vista fiscal. La problemática de cómo el diseño de las políticas económicas refleja tanto la incidencia transnacional de las prácticas institucionales y las ideologías económicas que estas encarnan no aparece en ninguno de estos relatos.

La primera perspectiva trata de la oposición total entre prudencia versus despilfarro. Tradicionalmente adopta el formato de cuento moral sobre la prevalencia absoluta de la política clientelista, la evasión fiscal, y la corrupción política entre 
Alemania, por una parte, y Grecia y los otros, por otra parte. En resumen, los países periféricos han gastado más de lo que pueden permitirse al excederse en tomar prestado a bajos tipos de interés facilitados por el euro. Esos bajos tipos de interés reflejan las valoraciones del mercado acerca del estado económico general dentro de la Eurozona, achacándose este a los esfuerzos de los miembros más productivos y no a los holgazanes de la periferia. De forma frecuente, especialmente en los medios de comunicación, esta oposición implica el reciclaje de estereotipos nacionales: por un lado, por ejemplo, los griegos son retratados como niños incapaces de controlar sus impulsos y, por otro lado, los alemanes son representados como tacañas amas de casa. Líderes de opinión de varios tipos han caracterizado la crisis de tres formas diferentes, una de las cuales es en términos de psicología colectiva. Así, Jürgen Stark (miembro alemán del Consejo del Banco Central Europeo) en el Financial Times (11 de febrero de 2015) dijo acerca de los países periféricos que "el déficit real es el fracaso de la elite política de muchos países y la falta de instituciones creíbles". El 17 de abril de 2015 Chris Giles (el editor económico del Financial Times) va un paso más allá al comparar a Grecia con un "niño" que necesita disciplina paternal. En ese mismo periódico y en la misma fecha, John Dizard, citando un libro de 1826, afirmó que en realidad esta era una historia muy vieja al efecto de que "La mayoría de los griegos no entienden correctamente el significado de préstamo [extranjero], sino que concluyen simplemente que es algún método europeo de hacer un regalo". Francesco Giavazzi, un reconocido economista italiano, anunció en el Financial Times (9 de junio de 2015) que los griegos habían optado por la pobreza al renunciar a "modernizar" su economía. Aparentemente, las políticas de austeridad impuestas desde fuera no habían jugado ningún papel en ayudarles a hacer efectiva su "elección". Una segunda perspectiva adopta los términos de incomprensión mutua. A este respecto, cabe citar la película española Perdiendo el Norte: una comedia sobre dos españoles desesperados que se van a Berlín en busca de trabajo, sin que ello responda a las expectativas creadas. Uno de ellos, Hugo, se lamenta acerca de que forma parte de "la generación más preparada en la historia de España" pero que ha acabado trabajando en la cocina de un restaurante de kebabs. Todos los alemanes son retratados como fríos, estrictos, serios y, por supuesto, rubios (Buck, 2015). Finalmente, y de forma notoria, existe una perspectiva que subraya la oposición en términos de resentimiento mutuo y antagonismo. El mejor ejemplo de ello es la controversia surgida en marzo de 2015 alrededor del posicionamiento del dedo izquierdo de Yanis Varoufakis, ministro de finanzas del gobierno griego liderado por Syriza desde enero de 2015. ¿Sacó su dígito ofensivo en un gesto vejatorio dirigido a Berlín al tiempo que hacía un llamamiento para que Grecia no hiciera frente a sus deudas? Él niega haber levantado lo que en alemán se llama "Stinkefinger" y afirma que el video de la conferencia de 2013 en Croacia había sido manipulado (Wagstyl, 2015). Durante gran parte de marzo del 2015 la prensa alemana, especialmente el tabloide Bild, propiedad del grupo editorial Springer, se mostró obsesionada acerca de si lo había hecho o no. Por su parte, los 
griegos han hecho un llamamiento a las reparaciones por parte de Alemania a cuenta de los gastos asumidos cuando fueron ocupados por el régimen nazi alemán durante la Segunda Guerra Mundial.

De forma menos frecuente, aunque en un tono más serio, los círculos académicos achacan enteramente la crisis de la Eurozona a una continuación de la crisis financiera por otros medios o al pobre diseño de la Eurozona. En el primero de los casos, la crisis económica se conceptualiza como endémica al capitalismo (por ej. Harvey, 2011). Desde los años 60 las descendientes tasas de ganancias en los negocios han necesitado constantes reestructuraciones para facilitar la recuperación, pero ninguna de ellas ha resultado ser duradera - nunca lo son-. En vez de ser resueltos, los problemas son desplazados a otra zona geográfica. En consecuencia y ante la crisis financiera global, las intervenciones estatales de 2008 promovieron déficits fiscales masivos por todo el mundo. La respuesta de la Eurozona fue la de endurecer la política fiscal y monetaria, lo que típicamente se explica dentro de esta perspectiva en base a, simplemente, ser "diferentes" de los Estados Unidos y China. Los Estados Unidos siguieron una política monetaria muy imprecisa y una política fiscal expansiva. China adoptó una política fiscal expansiva pero una política monetaria relativamente ajustada. La heterogeneidad de las economías de la Eurozona, por encima de todo la ausencia de un sistema común de calificación de bonos, significó que los países más expuestos a los mercados de bonos a través de préstamos para mantener los niveles de consumo y rescatar a sus bancos, estaban más abocados a la política de recortes; lo que se traduce en una "sinización" de las condiciones laborales y los bienes públicos. Como resultado, una nueva ronda de desarrollo desigual dentro de la Eurozona y nuevas posibilidades de beneficio para el capital internacional son los resultados probables, y no el equilibrio espacial entre los ingresos y la riqueza dentro de la Eurozona conforme se derivaría del estatus de miembro del área monetaria común.

Por supuesto, y este es el segundo relato bajo este enunciado, la Eurozona no es y no ha sido nunca y desde ningún punto de vista una zona monetaria óptima. Dicho sencillamente, las economías nacionales subsumidas dentro de la Eurozona con sus historias fiscales concretas, desproporcionalidades en sus estructuras industriales y patrones comerciales, y asimetrías en los flujos del capital encajan de forma anómala las unas con las otras (por ej., Piris, 2011; Polito y Wickens, 2013; Eichengreen, 2014). Más allá de esto, las medidas que podrían haber aumentado las complementariedades como la redistribución fiscal entre los países más y menos ricos y un bono soberano común estaban completamente fuera del alcance en el momento en el que el diseño de la Eurozona se estaba poniendo en práctica. En general estas cuestiones se consideraban, particularmente en Alemania, como pasos demasiado alejados. Por lo tanto, la crisis de la Eurozona es el resultado directo de que mientras los gobiernos nacionales tuvieron que hacer frente a la responsabilidad principal de rescatar a sus bancos tras el crash financiero de 2008, también se vieron obligados a recabar fondos externamente a través del mercado de bonos para finan- 
ciar los déficits públicos que tenían ahora debido al rescate y al declive de los beneficios por efecto del menguado crecimiento económico. Las instituciones centrales de la Eurozona, como el Banco Europeo Central y la Comisión, simplemente no tenían instrumentos adecuados a su disposición para responder por la Eurozona en su conjunto. En consecuencia, la crisis se convirtió en el forcejeo entre las economías más fuertes por imponer los términos bajo los cuales los más débiles podrían quedarse en la Eurozona a pesar del hecho de que los más fuertes habían violado con frecuencia y con anterioridad la responsabilidad monetaria que ahora imponían sobre los más débiles. Por lo tanto, la crisis de la Eurozona tiene más que ver con el déficit institucional que podría ser solucionado políticamente que con los síntomas de una crisis inmutable del capitalismo imposible de solucionar.

\section{Analizando la crisis de la Eurozona}

Existen, sin embargo, pocas dudas acerca de que la crisis de la deuda soberana en la Eurozona es un resultado directo de la crisis bancaria/financiera de 2008 (ver, por ejemplo, Bordo y James, 2013; Bordo y James, 2014). Su continuación se debe enteramente a otra cuestión, lo cual constituye el tema principal de este artículo. Para realizar este análisis es necesario hacer un breve repaso sobre el desarrollo de la crisis en la Eurozona.

La crisis financiera de 2008 comenzó con el colapso del llamado mercado de las hipotecas sub-prime o hipotecas basura en Estados Unidos, donde muchos bancos europeos habían realizado grandes inversiones. Fue el resultado de la conversión de la deuda de la banca en deuda gubernamental puesto que los gobiernos nacionales rescataron a los bancos y tomaron prestado del mercado de bonos para cubrir la tremenda pérdida de beneficios provocada por la fuerte caída del crecimiento económico. En términos relativos, el mayor peso de la deuda recayó en los países del sur de Europa e Irlanda cuyas economías eran o bien más vulnerables a los vaivenes en el mercado exterior de bonos debido a sus sobredimensionados mercados hipotecarios (como en Irlanda y España), o bien aquejadas por la sobrecarga existente en la deuda pública resultante de préstamos dirigidos a la provisión de bienes públicos que no se habían correspondido con un crecimiento de los ingresos al mismo nivel (como en Grecia e Italia). Mayoritariamente los bancos que extendieron el crédito a las economías periféricas procedían de Alemania, Francia, Suiza y Reino Unido. En el año 2010, los bancos de los países miembros de la Eurozona estaban expuestos a un equivalente de 727 mil millones de dólares en España, 402 mil millones de dólares en Irlanda y 206 mil millones de dólares en Grecia. Es la conversión de la deuda privada en deuda pública lo que se sitúa en el centro de la crisis. Por lo tanto, y en el caso de Grecia por poner un ejemplo, lo que en diciembre de 2009 era una deuda íntegramente privada (de los bancos) se ha convertido en deuda pública que debe ser pagada a la troika del BCE, la UE y el FMI (Figura 1) como efecto de las 
acciones de los gobiernos nacionales. Al menos para el caso de Grecia, el cambio es sustancial en cuanto a qué bancos ("de qué país") detentaban la deuda en diciembre de 2009 por un parte y, qué gobiernos tienen la ahora convertida deuda pública a fecha de septiembre 2014. Lo que está claro es que los bancos ya no son quienes poseen la deuda griega, sino que son los gobiernos de la Eurozona los que la han asumido. La crisis reside en la imposibilidad de que Grecia pague su deuda a los otros gobiernos nacionales sin que siga tomando prestado de la troika dada la imposición de políticas de austeridad por parte de las autoridades de la Eurozona (y el FMI) designadas para restringir los continuos préstamos del sector público pero que, al mismo tiempo, impide que los gobiernos incurran en gasto para favorecer el crecimiento económico que podría (potencialmente) aumentar los beneficios gubernamentales y reducir los costes de los préstamos privados en el mercado de bonos.

Figura 1. La exposición cambiante de los bancos y Estados de la Eurozona frente a la deuda griega (diciembre 2009 - septiembre 2014)

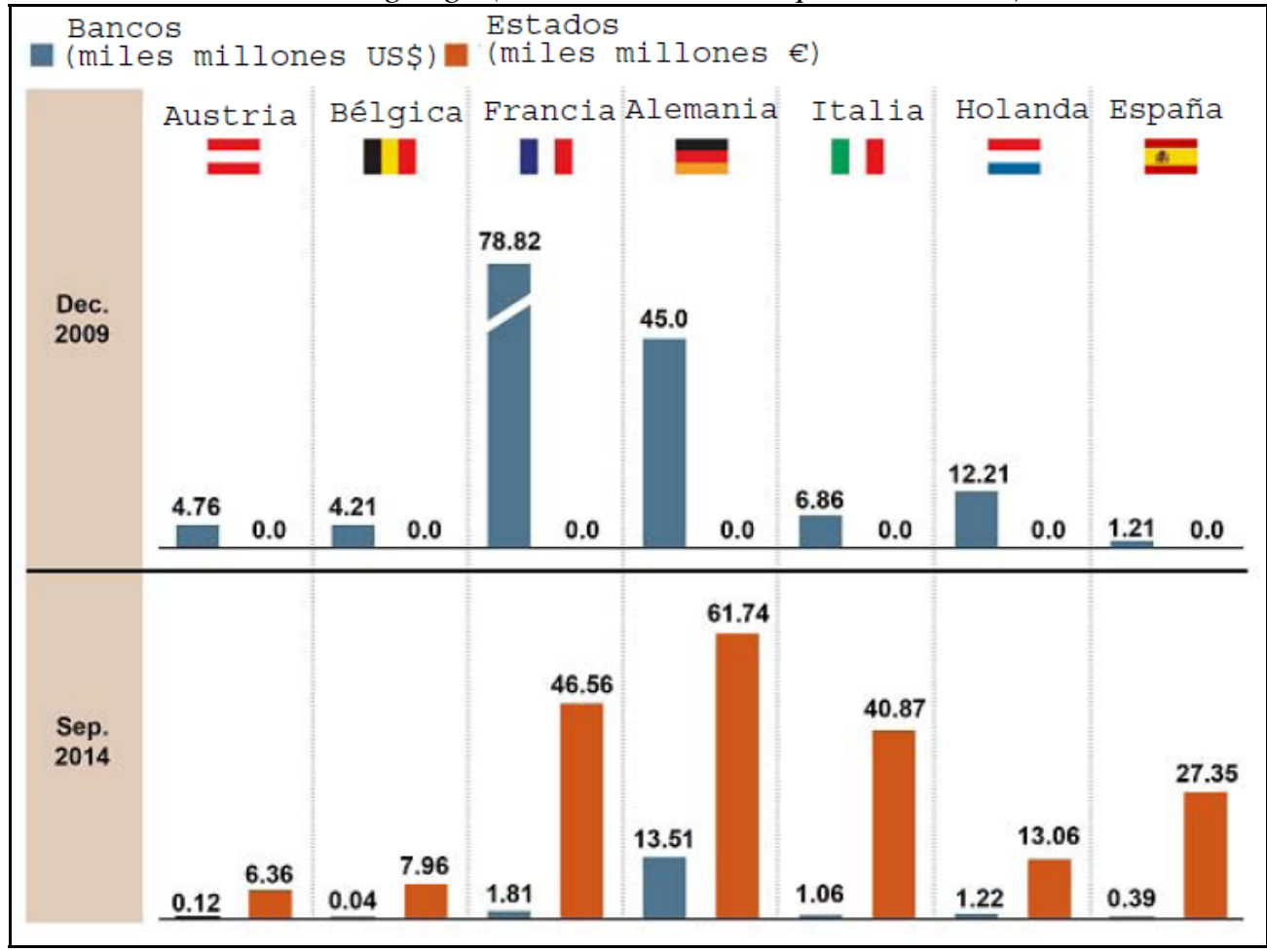

Fuente: Banco Central Europeo. 
Figura 2. Deuda pública bruta en términos porcentuales con respecto al PIB. Comparativa entre Estados Unidos, Japón, Gran Bretaña y la Eurozona (1980-2014)

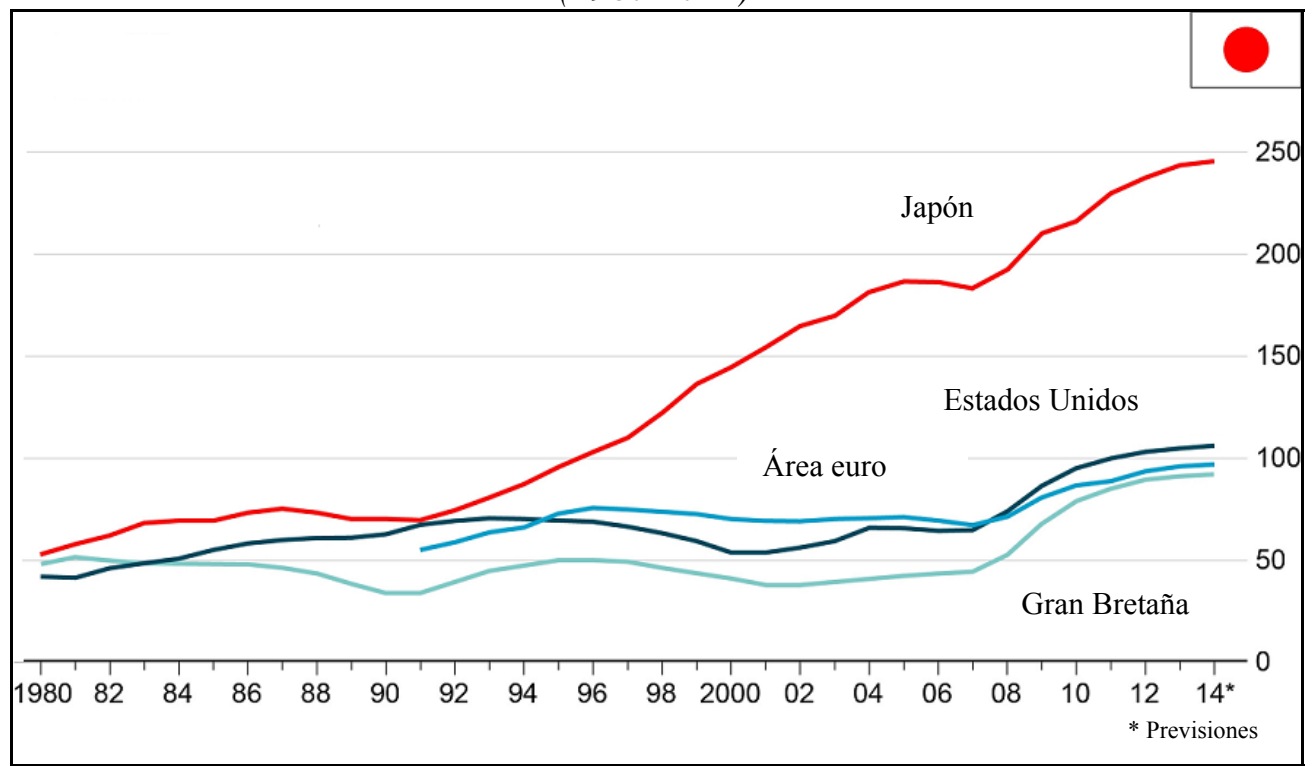

Fuente: FMI <Economist.com/graphicdetail $>$

En torno al desarrollo de la crisis, es necesario mencionar cuatro puntos. El primero es que, con la excepción de Italia, la carga de la deuda en los países periféricos es relativamente pequeña (en total menos de 500 mil millones de dólares) comparada con la deuda pública absoluta de los miembros de la Eurozona como Alemania y Francia (entre 2500 y 3000 mil millones de dólares, respectivamente) e incluso en términos de la proporción entre la deuda y el PIB de Irlanda, Portugal y España (en el 80-95\%), que es más o menos igual en el año 2014 que los países supuestamente más "fuertes" (para Alemania y Francia fue del 83\%). En relación con esto último, Grecia es el caso más atípico. El segundo punto se refiere a que el problema de la deuda total de los gobiernos de la Eurozona es muy similar al de Estados Unidos y el Reino Unido pero mucho menor que, por ejemplo, la de Japón (Figura 2). Pareciera como si la crisis de la Eurozona atendiera a razones distintas del tamaño de la deuda pública o la "amenaza" global a la moneda procedente del endeudamiento del sector público, lo cual nos remite al tercer punto. En 2008-9, muy al comienzo de la crisis financiera, muchos gobiernos alrededor del mundo, desde Estados Unidos a China, intervinieron para utilizar el gasto público para estimular el repunte económico, lo cual fue efectivo a varios niveles. Pero en la Eurozona como tal, el estímulo fiscal no se consideró una opción en absoluto. Más bien al contrario, la consolidación fiscal y las reformas estructurales se convirtieron en las exigencias centrales. Durante el periodo 2010-14 la troika recompensó la 
austeridad fiscal con préstamos que sirvieron para pagar antiguas deudas. Por ejemplo, en 2010 Grecia recibió 110 mil millones de dólares a cambio de un recorte en los salarios públicos y las pensiones de un 20 por ciento; Irlanda recibió 60 mil millones de dólares a cambio de un recorte del 24 por ciento en el gasto público. El impacto de estos recortes y las políticas de austeridad asociadas a ellos han sido devastadores para las economías en cuestión y por encima de todas ellas, para la economía griega. En este país, entre los años 2009 y 2014, el PIB real agregado cayó un 27 por ciento, lo cual supuso una caída del gasto real en un tercio. La tasa de desempleo alcanzó el 28 por ciento en 2013, mientras que el gasto público cayó un 30 por ciento entre 2009 y 2014. Bajo tales condiciones la posibilidad de que aumente la capacidad para alcanzar los objetivos fiscales y económicos (tales como el descenso del gasto público en relación con el PIB, la mejora en la flexibilidad del mercado de trabajo, etc.) dictados por la troika es muy pequeña. Irónicamente, y dado que son los griegos de a pie quienes han tenido que soportar en mayor medida la carga del "ajuste", como señala un autor:

La mayor parte de los préstamos oficiales a Grecia no se realizaron en absoluto en su beneficio, sino en el de los inútiles acreedores privados. Los acreedores también tienen el deber de estar vigilantes. Si son negligentes se arriesgan a sufrir grandes pérdidas. Si los gobiernos quieren salvarlos, deberían decirles a sus propios contribuyentes que van a pagar (Wolf, 2015: 10).

El cuarto punto es fundamental para entender por qué se tomó el camino de la austeridad y el proceso de toma de decisiones dentro de la Eurozona es crucial en ese sentido. En su manera de proceder reflejaba los orígenes monetaristas de la Eurozona y el modelo alemán del Banco Central Europeo como entidad tecnocrática más allá de la "influencia política" y con un modus operandi basado en reglas establecidas. La política monetaria venía acompañada de un menú de política económica bastante limitado y donde el estímulo fiscal constituía un estricto tabú. Ello se debía no solo a que la política fiscal se encontraba en manos de los gobiernos miembros sino también a que el modelo alemán de "buenas prácticas" bloqueaba su uso como una manera de salir potencialmente de la crisis. La apuesta por la austeridad fiscal era, por lo tanto, absolutamente central al modelo de la Eurozona, no simplemente como un elemento ad hoc que "ocurrió" y distanció a la Eurozona de, por ejemplo, Estados Unidos y China.

La perspectiva de la austeridad se fundamentaba en dos premisas falsas a decir por los orígenes de la crisis financiera en Europa en 2008. Estas no tienen mucho sentido dentro de un sistema de capitalismo global, aunque hayan podido tenerlo con anterioridad. Una es que se daba por hecho la correspondencia entre banco/país que ya no resulta operativo si miramos a la manera en cómo ha evolucionado la crisis. La banca ha sido internacionalizada, mientras que la Eurozona sigue sin tener mecanismos para regular esto excepto a nivel nacional. Así, incluso si las deudas 
bancarias se contraen en otra parte, se supone que los países de origen han de ser los acreedores que los salven del colapso. Una regulación bancaria a nivel de la Eurozona apoyada por el bono europeo habría evitado que la crisis escalara en una serie de crisis bilaterales - Irlanda y la Eurozona, Grecia y la Eurozona, etc.- que requería medidas de austeridad país por país en el sentido asumido por el modelo alemán de buenas prácticas monetarias y fiscales. La segunda de las premisas equivocadas es que reformas rápidas en el mercado laboral y en las políticas de bienestar (como respuesta a lo cual se liberaría más crédito para pagar viejas deudas) son fundamentales para corregir lo que sucedió después del año 2008. Como hemos visto, sin lugar a dudas, la crisis fue primero una crisis de movilidad de la banca/capital que de bonos, de lo que se infiere que la atención que atrajo el gasto del sector público estaba mal enfocada. El principal factor explicativo de la crisis de bonos/deuda no era el gasto público. Tampoco se trataba, en primer lugar, de una crisis sobre la competitividad global de las economías nacionales; sin embargo, el enfoque exclusivo en la austeridad lo ha convertido en eso. La globalización ha venido teniendo impactos negativos en economías de la Eurozona como la de Italia mucho antes del estallido de la crisis financiera en 2008 - y esto ha continuadoAl mismo tiempo, las diferencias nacionales a lo largo y ancho de la Eurozona en relación a la eficiencia del mercado de trabajo no son tan grandes como el folclore económico en relación con Italia, España y Grecia podría hacernos creer. A pesar de que hay ineficiencias reales en, por ejemplo, el registro de empresas y en la protección a ciertas categorías laborales, estas reflejan diferencias de grado más que de tipo entre los países de la periferia y el centro de la Eurozona. La supuesta diferencia en la flexibilidad del mercado laboral entre Alemania por una parte y por otra parte, por ejemplo, Grecia, no es tan grande como se podría pensar si seguimos las posturas de los defensores de la austeridad. De hecho, de acuerdo con datos de la OCDE, los contratos de trabajo regulares han sido más flexibles en Grecia que en Alemania durante algunos años (Figura 3). Tales contratos ascendieron a un 73 por ciento del empleo griego en el año 2013. Por lo tanto, más que rigideces institucionales, factores como la dependencia excesiva en los bonos, y no en los impuestos para elevar los ingresos y los impactos de la globalización en los negocios locales, han jugado un papel más importante en crear la inestabilidad fiscal que más tarde la crisis bancaria ha convertido en una crisis de deuda a gran escala.

Desde una perspectiva, se puede ver este resultado como el choque entre diferentes "variedades" del capitalismo, con una dominante, el modelo alemán que dirige la Eurozona, adaptado de forma deficitaria tanto a los tiempos como a la escala de la Eurozona en su totalidad. Sin lugar a dudas, como arguye Hall (2014: 1225), el diseño de la Eurozona "ignoraba diferencias duraderas entre las economías políticas de la UE a favor de una economía ideal en la que, de acuerdo con el pensamiento clásico, los mercados operados por actores altamente informados cuya gestión requería instituciones mínimas del tipo de las que poseía la unión”. Pero el problema de la Eurozona era mucho mayor que esto. Se trata de la proyección de un 
modelo nacional ideal hacia otros en un contexto global en el que las fronteras nacionales tienen efectos limitados en la conformación de los flujos del capital, los bienes y las personas más acordes al caso. De forma más específica, y en este sentido Jessop (2012: 102) resulta ser una útil guía teórica, "la sombra del neoliberalismo dominado por las finanzas" que surge más allá de las costas europeas, pero al que las prácticas financieras europeas tratan de parecerse cada día más, cayó sobre una Eurozona conformada por economías definidas por una serie de modelos capitalistas (economías de mercado coordinadas como las de Alemania, dirigista como la Francia y clientelista/corporativista como la de Italia y Grecia), pero integradas, si acaso este es el término correcto, a través de "las premisas y operaciones del Banco Central Europeo, cuyo paradigma político se derivaba en buena medida de modelo alemán y que ponía una fe excesiva en la capacidad de las fuerzas del mercado para generar convergencia ascendente a través del rendimiento económico".

Figura 3. Índice de la OCDE sobre la rigidez en la protección del empleo para contratos regulares y temporales (2000-2013). Comparativa entre Grecia, Portugal, España y Alemania (un bajo índice expresa mayor flexibilidad)

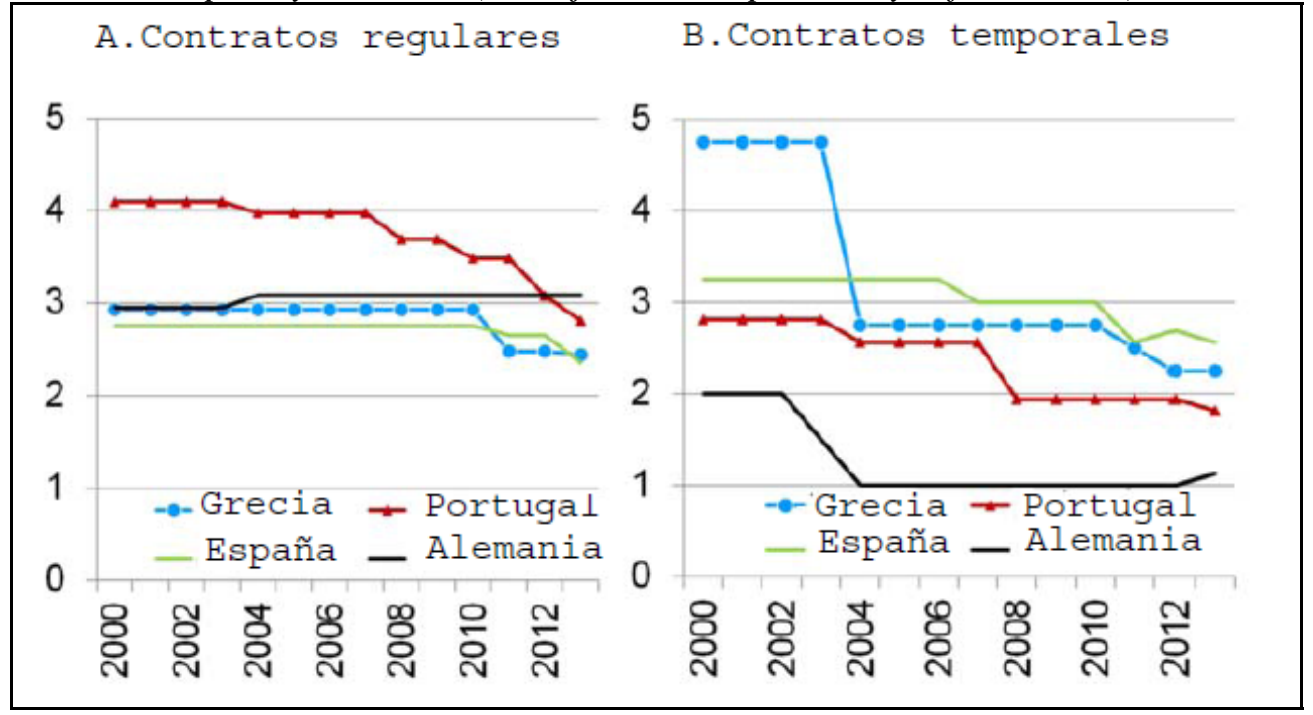

Fuente: elaboración propia

Dentro del diseño de la Eurozona el carácter potencialmente problemático de este "capitalismo heterogéneo" ha podido ser detectado en estadios anteriores de su historia (por ej., Grahl, 2001). Quizá la experiencia desde los años 80 del banco privado alemán más grande, Deutsche Bank, es ilustrativa del impacto devastador de la confusa combinación multiescalar de las actividades globales y el modelo 
económico nacional ideal que supone el capitalismo heterogéneo dentro del molde de la Eurozona. A partir de 1989, la dirección del banco se propuso la transformación de la entidad de banca corporativa y minorista basada en Alemania en banca corporativa global y de inversiones (por ej., Gapper, 2015); pero permanece atrapado entre los dos imperativos. En el corazón de la base industrial alemana, donde su denominación actúa como recordatorio de sus raíces, algunos líderes en los últimos tiempos han aspirado a liquidar la división minorista y convertirse en un rival global frente a Goldman Sachs. Sin embargo, esta opción se ha encontrado con mucha resistencia tanto dentro del banco como por parte de sus clientes alemanes. Los periódicos alemanes tanto de izquierdas como el Süddeutsche Zeitung como el diario de negocios Handelsblatt han clamado por la vuelta al "aburrido" modelo nacional-territorial centrado en los préstamos a los hogares y empresas alemanas. Es más, el banco tiene que hacer frente a un mercado bancario minorista increíblemente competitivo dentro de Alemania. Por lo tanto, está atrapado por una parte entre la lógica de la especialización y la globalización y, por otra parte, por la de permanecer dentro de los confines de la economía territorial alemana. Ello ilustra el amplio problema macroeconómico de utilización del modelo histórico alemán como modelo de gestión económica territorial en una escala que atraviesa las políticas económicas que en la actualidad están penetradas por una lógica neoliberal en la que el capital no conoce fronteras. Esta es la tragedia de la Eurozona, así como el fundamento de su crisis particular (por ej., Atkins, 2011; Beck, 2013).

\section{3. ¿Qué es la Ordnungspolitik?}

En su diseño, la Eurozona aparecía como el resultado de compromisos sobre los roles relativos de las instituciones nacionales y las nuevas instituciones de la Eurozona, pero la mayor institución de la Eurozona, el Banco Central Europeo, y las políticas monetarias que dieron forma al funcionamiento de la Eurozona desde el principio tomaron como modelo el modelo de Alemania. La justificación concreta de la austeridad ante la crisis reciente también se deriva del modelo alemán y no es la misma que funciona, por ejemplo, en Gran Bretaña, o que inspira a pequeños gobiernos conservadores en Estados Unidos. En los últimos casos se trata de adelgazar o hacer retroceder al Estado, mientras que en el primer caso se trata de que el Estado adopte un papel adecuado en relación con los mercados (Blyth, 2013: 133). La crisis ha hecho aumentar el miedo en algunos círculos alemanes de que estando el Banco Central Europeo bajo la dirección de un italiano, Mario Draghi, "en vez de exportar la Stabilitätskultur (cultura de la estabilidad) del Bundesbank al resto de Europa como ellos habían esperado", el "cerco geoeconómico" a Alemania tendrá como resultado "la importación de la cultura de la moneda débil a Alemania" (Kundnani, 2015: 112). No es difícil trazar las raíces de este miedo. La preocupación por la estabilidad monetaria procede de la amarga experiencia de la historia 
alemana moderna. En concreto, tras la década de los $50 \mathrm{y}$ con el fin del nazismo, una visión particular sobre la relación entre Estado y mercado vino a prevalecer entre la elite política alemana, especialmente dentro del Partido DemócrataCristiano, que se distingue de la que ha operado históricamente en, por ejemplo, el Reino Unido y los Estados Unidos. El llamado ordoliberalismo ha dominado el pensamiento y la práctica económica en Alemania desde la década de los 50 de la misma manera en que el keynesianismo lo ha hecho en el Reino Unido y Estados Unidos después de la Segunda Guerra Mundial y hasta los años 80. La principal diferencia es que:

Los ordoliberales consideran que para empezar el Estado tiene un papel en el establecimiento de las condiciones marco necesarias para que los mercados operen efectivamente. Sin embargo, el Estado con el que están satisfechos no es el gestor macroeconómico centrado en el lado de la demanda económica y que resultó del Nuevo Liberalismo Británico. Más bien, el Estado ordoliberal es quien pone las reglas que facilitan la competición y ayuda a los ajustes del mercado a través del desarrollo de mecanismos e instituciones económicas (Blyth, 2013: 133).

Es esta visión distintiva del rol del Estado la que previene la resolución fácil de la crisis a través de la condonación de la deuda y del estímulo fiscal mutuo por parte de los países miembros de la Eurozona. Sin embargo, por supuesto, como hemos señalado con anterioridad, Alemania en sí misma ya no es la economía territorial aislada que dirige su propio destino, tal y como asume este modelo. Sea como fuere, la imagen poderosa de una economía construida alrededor de la Ordnungspolitik o un marco constitucional basado en reglas para modelar los mercados pero no intervenir en ellos guió el desarrollo de la Eurozona y, hasta cierto punto, ha dirigido la política económica en el trascurso de la crisis en la Eurozona. Esto último puede ser llevado a la exageración puesto que, como han demostrado varios autores, a pesar de estar inspiradas en el ordoliberalismo las políticas que han guiado el tratamiento de la crisis de la Eurozona también han exhibido pragmatismo y variación al respecto de qué términos de este marco de la Ordnungspolitik se han de enfatizar (Jacoby, 2014; Feld et al., 2015).

No obstante, merece la pena subrayar el enfoque general de este marco en un llamamiento al orden como camino a la estabilidad. Entre otras cuestiones, ello implica la imposición de una estricta disciplina presupuestaria sobre las entidades gubernamentales, asegurarse de que no se desarrollan cárteles empresariales, la provisión de redes de seguridad social, así como asegurar una política del orden y la estabilidad. Aunque a veces simplemente asociado a una escuela de pensamiento económico que, con orígenes a principios de la década de los 30, vino a capturar la imaginación de los líderes políticos y se filtró a toda la sociedad alemana en los 50, la experiencia histórica real también se ha involucrado en el fortalecimiento del control y la persistencia de esta perspectiva general incluso si su relevancia para las 
expectativas de la Eurozona han estado en cuestión de forma creciente. Dos periodos de inflación monetaria desastrosa en 1923-4 e inmediatamente después de la Segunda Guerra Mundial llevaron a la búsqueda de una alternativa tanto para el laissez faire capitalista y el capitalismo de base industrial del periodo nazi. En calidad de potencia ocupante, el gobierno de los Estados Unidos promovió activamente un enfoque de política competitiva y anti-trust como elemento importante de la política gubernamental. Ello fue adoptado con más celeridad en Alemania que en, por ejemplo, Italia, donde no existía tal coyuntura o una preocupación propia por limitar los cárteles (Segreto y Wubs, 2014). La resultante "economía social de mercado" en la Alemania occidental de los 50 por lo tanto estaba basada en el contrato social por el cual el gobierno establece las reglas que privilegian la estabilidad de precios, la libertad de los contratos privados, la competición entre empresas y no el consumo como la clave del estímulo para el crecimiento económico, así como el prototipo de la economía doméstica como modelo para la economía nacional. El notorio éxito económico de la Alemania occidental durante los cincuenta años posteriores se ha asociado popularmente con esta receta político-económica.

Merece la pena destacar el argumento de la experiencia histórica como más significativo para la perpetuación de este marco que la inercia de la continuación de un modelo económico académico particular adoptado por parte de la elite política. Por una parte, ello da cuenta de la popularidad general con la que cuenta el modelo de la austeridad para los países periféricos entre los alemanes de a pie. Un "hábito de la memoria" transmitido en las familias y en el discurso oficial ha convertido la amenaza de la inflación, tal y como se experimentó en los años 20, en la medida central de la política monetaria. Incluso sin que existan evidencias de las tendencias inflacionistas (de hecho, se ha señalado la tendencia contraria) la retórica de la estabilidad de precios ha dominado el discurso popular alemán (O’Callaghan, 2012). Esta conclusión se refuerza por el hecho de que el diseño inicial de la Eurozona se asociaba popularmente en Alemania con la exportación del orden monetario alemán al resto de Europa (Kaelberer, 2005). El desarrollo ordenado es bueno para otros así como lo es para Alemania (por ej., Sinn, 2014; Hillebrand, 2015). Dentro de sus opciones políticas, los líderes alemanes como Angela Merkel se han visto limitados por el compromiso popular hacia la Ordnungspolitik abrazado por los alemanes de a pie (por ej., Wagstyl y Vasagar, 2015).

Por otra parte, la reciente experiencia de Alemania en relación con la estanflación de los 70, la reunificación de los 90, las reformas económicas de principios de los años 2000, apuntan a lo mucho que se pueden beneficiar los demás si adoptaran el enfoque alemán. En los años 70 los gobiernos alemanes se esforzaron por comprometer a los gobiernos de Estados Unidos y otros países para terminar con la estanflación a través del aumento de las tasas de interés y de las políticas de austeridad. Se podría decir entonces que el giro hacia el neoliberalismo y lejos del keynesianismo británico y estadounidense le debe algo al evangelismo alemán por las estrictas medidas presupuestarias (Germann, 2014). El proceso de reunificación 
alemana en los años 90, visto como enormemente exitoso por parte de los alemanes occidentales, aunque no en la misma medida por los alemanes orientales tras haber sido integrados en la nueva economía, ha reforzado el apego al énfasis en el orden y la estabilidad. Sin embargo, tal y como Gerhard Ritter (2011) ha demostrado con considerable detalle, los costes de la reunificación fueron infraestimados de forma sistemática y llevaron aparejada la intervención directa del Estado para conseguir un nivel de convergencia económica mayor del que se podía esperar del "modelo" convencional. Como respuesta a algunos problemas económicos derivados de la reunificación y de los desafíos de la globalización, a principios de los años 2000, el gobierno alemán de turno reformó los mercados de trabajo para hacerlos más flexibles y las empresas alemanas más flexibles en los mercados de exportación (Kundnani, 2015). Sin dejar de prestar atención al gasto del sector público, se considera esta adaptación exitosa como la principal razón por la cual la economía alemana ha sobrevivido a la crisis financiera sin resultar dañada en comparación con los otros miembros de la Eurozona, especialmente en la periferia del sur. Puede que la Ordnungspolitik sea un producto alemán, pero este está disponible para la exportación. Sin embargo, al final en el transcurso de la crisis de la Eurozona satisfacer al público alemán ha resultado ser más importante que cambiar las tornas para facilitar su resolución (Bulmer, 2014).

\section{Los límites de la Ordnungspolitik en el capitalismo heterogéneo}

El modelo alemán idealizado es un reflejo de la economía social de mercado que se desarrolló con éxito en Alemania a partir de la década de los 50. El problema es que ya no describe de forma adecuada el actual funcionamiento de la economía alemana y sus relaciones con el capitalismo global más amplio en el que se encuentra inscrita. El punto aquí no es que el modelo alemán ha "convergido" con o se ha subsumido bajo un modelo nacional alternativo, como único sustituto viable, tal y como sugeriría la literatura sobre las variedades del capitalismo (por ej., Hall y Soskice, 2001), incluso aunque seamos escépticos en que esto sea probable. Lo que ha ocurrido es que la economía alemana ha estado sujeta a la "liberalización progresiva" (Streeck y Yamamura, 2001: 36). Ello ha ocurrido debido a la ruptura del consenso social sobre el cual descansaba la economía social de mercado (relaciones laborales cooperativas y demás) y el peso creciente del sector financiero en un país en el que la burguesía industrial era dominante políticamente. Si nos centramos simplemente en la persistencia de arreglos institucionales que, en principio, han distinguido a Alemania históricamente podemos estar perdiendo de vista el lento derrumbe de las soluciones políticas que los sustentaban (Coates, 2000). El debilitamiento conjunto de los sindicatos y la movilidad en aumento del capital a través de fronteras nacionales ha caracterizado a Alemania tanto como otros lugares durante los últimos cuarenta años. Esto ocurre porque la economía alemana no es un 
"Estado aislado" sino sujeto a la regulación institucional a otros niveles de gobernanza (incluyendo la UE y la Eurozona) y a las mismas presiones sobre la actuación económica procedente del capital global —-fenómeno común y en aumento a nivel mundial一.

Por lo tanto, la experiencia reciente en Alemania sugiere que la Ordnungspolitik es tan problemática a nivel doméstico como lo es para terceros países. En primer lugar, la actual posición económica de Alemania es insostenible. Su gran superávit comercial ha sido alcanzado a expensas del correspondiente déficit por cuenta corriente de los países periféricos en crisis (Tooze, 2012). El intento de que los demás adopten la economía manufacturera orientada a la exportación como modelo de crecimiento (implícito en el énfasis sobre la reforma del mercado laboral como clave para el aumento de la productividad) es simplemente ridículo cuando el propio crecimiento alemán depende precisamente de que ellos no adoptan esta medida. Incluso cuando las empresas alemanas han diversificado sus exportaciones a China y otros países, todavía son altamente dependientes de los socios comerciales europeos incluidos muchos de la Eurozona. Fueron los exportadores alemanes quienes abogaron más fuertemente por el proyecto del euro en los años 90 cuando el escepticismo dominaba entre los sectores ordoliberales de la opinión pública alemana. Más allá de la perspectiva de estancamiento global en los próximos años (e.g., Pritchett y Summers, 2004), quizá el mayor desafío al que se enfrenta la economía alemana es el demográfico. En los próximos quince años Alemania se enfrenta al mayor aumento en la ratio de dependencia de las personas en edad avanzada que ningún otro país europeo debido a una tasa de fertilidad muy baja. Ello significa que habrá mucha menos gente en el grupo de edad para trabajar y pagar impuestos para los jubilados al tiempo que el número de jubilados ejerce una creciente demanda sobre las presiones y el ámbito sanitario. El influjo de migrantes jóvenes puede atemperar esta escasez pero no tanto, ya que la caída del empleo entre la población nativa es mucho mayor que el número de nuevas llegadas (Economist, 2015).

En segundo lugar, los últimos gobiernos alemanes no han conseguido sacar provecho de préstamos con tipos de interés increíblemente bajos para pagar por mejoras en infraestructuras, energía, gastos y pensiones, a resultas de lo cual la austeridad ha sido dañina a nivel nacional (por ej., Economist, 2014). No solo se han estancado los salarios mínimos desde el año 2000, sino que el gasto en bienes públicos como en carreteras e investigación industrial y desarrollo ha crecido a una tasa más baja que en Reino Unido y Francia. Recientemente un comentarista alemán decía que Alemania es en la actualidad un país con una infraestructura obsoleta cuyo nivel de productividad global es cerca de la mitad de lo que era en los 90 (Fratzscher, 2014). Un indicador de que las cosas no están tan bien en el país es el gran aumento de huelgas a lo largo de los últimos años. La mayor parte de estas han afectado al sector servicios donde se han concentrado la mayor parte de los trabajos. Las manufacturas orientadas a la exportación se han visto mucho menos afectadas, 
siendo este el sector más próspero en los últimos años. Pero la privatización progresiva de los antiguos servicios públicos, el crecimiento del infraempleo y el empleo de mala calidad, y el aumento de las disparidades salariales y la desigualdad en los ingresos han contribuido a la acentuación de la militancia laboral en otros sectores de la economía (Streeck, 2015).

En tercer lugar y a modo de conclusión, la fuerza de la economía alemana bajo el capitalismo heterogéneo ha recaído desde los años 70 en sus manufacturas orientadas a la exportación. Solo ella entre los grandes países capitalistas industriales ha conseguido no solo mantener sino aumentar su pericia en este sector a nivel global (Figura 4). Si esta orientación es sostenible o no a la luz del declive de la investigación y el desarrollo, la creciente competición exterior, y la alta probabilidad de que la economía mundial sufra estanflación durante los próximos años son incógnitas aún por resolver. Sin embargo, es este éxito, que no parece tener mucho que ver con ningún aspecto de la Ordnungspolitik, lo que ha situado a Alemania al margen de la Eurozona. Pero tal y como se ha mencionado con anterioridad, tratar de imitar a Alemania en este aspecto puede que, por un lado, dañe la economía alemana, y por otro lado, podría eliminar potencialmente aquellos mercados que en la actualidad constituyen dos tercios de las exportaciones manufacturadas alemanas. Ahí es donde reside el límite de la Ordnungspolitik a nivel de la Eurozona como conjunto.

Figura 4. La habilidad exportadora de Alemania en comparación con otros países del G6 + China (como \% del PIB) ilustra las limitaciones que se encuentran los

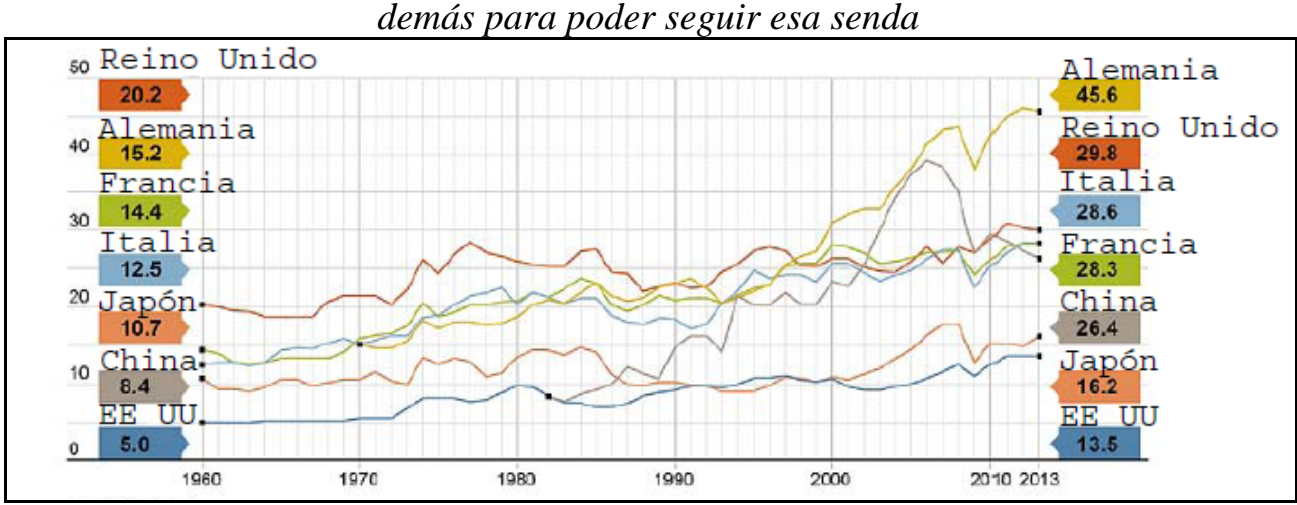

Fuente: Banco Mundial

\section{La tesis sobre el desajuste territorial y la crisis de la Eurozona}

La crisis de la Eurozona es una crisis basada en la aplicación de un modelo idealizado a la construcción y gestión de un área monetaria que se desarrolló en un con- 
texto nacional específico y que ya no resulta útil para describir los dilemas económicos que se deben afrontar en ese contexto. Además, ha resultado ser absolutamente ineficiente para la resolución de la crisis. Está claro que convertirse en un miembro de la Unión Europea no vino acompañado de la exigencia de ajustarse a estándares macroeconómicos básicos (incluida la elaboración de informes) y que no existían mecanismos institucionales creíbles para asegurar objetivos fiscales comunes, coordinar crisis de gestión o compensar las diferencias cíclicas de auge y caída entre los diferentes Estados miembros. En lugar de ese tipo de instituciones, el "paradigma político" (Jessop, 2012) ha sido el de las prácticas y las normas basadas en el modelo alemán cuyos pasos debían ser seguidos por los Estados miembros para conseguir la convergencia. La brecha entre el precursor histórico de este modelo, Alemania, y los otros Estados miembros era mayor para el caso de las economías periféricas de la Europa del sur. En este sentido, no se prestó atención al "reescalamiento" de este modelo a partir de la experiencia alemana y para con la Eurozona en su conjunto. Como hemos visto, la economía alemana requería que estos países tuvieran una balanza de pagos deficitaria frente a Alemania de forma que la máquina de exportación alemana pudiera funcionar. Más allá de eso, las distintas economías periféricas tenían distintas debilidades y fortalezas, de las cuales solo algunas era complementarias con Alemania y otros países del norte de Europa. Inicialmente, el modelo de gobernanza en la Eurozona se desarrolló dando prioridad al objetivo anti-inflacionista de los tecnócratas del Banco Central Europeo, lo cual era opuesto a la utilización continuada de la devaluación de la moneda para lograr competitividad en las exportaciones por parte de gobiernos como el de Italia. Por lo tanto, en su conjunto, la heterogeneidad de las estructuras económicas de los Estados miembros y el modelado del régimen de la Eurozona a imagen y semejanza de las prioridades de la Ordnungspolitik hacían imposible que se pudieran conseguir para la Eurozona los supuestos beneficios que una vez habían operado dentro de Alemania. Por supuesto, la ampliación del modelo de esta manera ignoraba el hecho de que una "transferencia" del exitoso modelo alemán a economías fallidas en los márgenes de la Eurozona no tenía ningún sentido, más aún cuando la misma Alemania estaba inscrita en un capitalismo mucho más heterogéneo con el cual su tan cacareado modelo histórico no guardaba mucha o ninguna similitud. La crisis de la Eurozona se ha demostrado irresoluble dentro de los términos establecidos dentro de la Eurozona misma debido al fracaso en el reconocimiento de estas realidades: por un lado, el desajuste territorial entre Alemania como modelo para otras economías nacionales, problemática en sí misma dado su carácter actual y los problemas a los que se enfrenta la economía alemana hoy en día; y, por otra parte, la imposibilidad absoluta de establecer a nivel de la Eurozona los términos y condiciones de una imposición satisfactoria de ningún tipo de Ordnungspolitik. 


\section{Conclusión}

Es necesario que el "excepcionalismo macroeconómico alemán" como lo llama Wolfgang Munchau (2014), sea discutido de forma más central en relación a la crisis de la Eurozona. Es más, la verdadera razón por la que es una crisis es debido a la imposición de un modelo de austeridad que no encaja con los parámetros mismos de la crisis. La crisis es una crisis de intervención gubernamental para rescatar a los bancos y no tanto una cuestión de excesivo gasto público. Ésta no se ha resuelto debido a la narrativa dominante que guía a la Eurozona y que procede de la tradición alemana de la Ordnungspolitik. Como espero haber demostrado, el modelo político-económico que ha resultado de ello es una pésima guía para la elaboración de políticas que permitan la resolución de la crisis. En primer lugar, no se puede aplicar a un número tan heterogéneo de economías como las de la Eurozona. Esto no va a ocurrir por arte de magia o por generación espontánea. Los gestores de la Eurozona deben reconocer la "polifonía" que existe en el corazón de esta empresa (por ej. Zielonka 2014). Si continuar por la senda de la "construcción" de una Europa integrada sobre el proyecto demócrata-cristiano de Alemania tiene más peso que la fidelidad a un modelo económico-espacial anticuado, entonces esta es la dirección que debe seguir el actual liderazgo alemán, independientemente de lo que ocurra con el caso griego. En segundo lugar, la Ordnungspolitik ya no representa el carácter heterogéneo de la propia economía alemana que también hoy sufre las políticas basadas en sus restricciones. En tercer y último lugar, la crisis de la Eurozona no es una crisis del Capital como tal, ni tampoco sobre el desajuste entre la política monetaria a una escala (la de la Eurozona) y la política fiscal a otra escala (la nacional). Es una crisis provocada por el inadecuado diseño de la Eurozona basado en el anacronismo del modelo histórico de la economía alemana. Hasta que esto no sea reconocido no se hará ningún progreso para resolver la crisis o para reconstruir una Eurozona que se ajuste a la verdadera naturaleza de las economías de sus Estados miembros, incluyendo también la de la propia Alemania.

\section{Bibliografía}

Atkins, R. (2011) "Germany and the Eurozone: marked by the miracle". Financial Times, 20 de Septiembre.

Beck, U. (2013) German Europe. Cambridge: Polity Press.

Blyth, M. (2013) Austerity: The History of a Dangerous Idea. Nueva York: Oxford University Press.

Bordo, M., y James, H. (2013) "The European crisis in the context of the history of previous financial crisis". Bank of Greece Conference, 23-25 Mayo.

Bordo, M., y James, H. (2014) The European crisis in the context of the history of previous financial crises. Journal of Macroeconomics, vol. 39 (B), 275-84. 
Buck, T. (2015) “The reel-life struggles of Spain's footloose millennials". Financial Times, 16 de Abril.

Bulmer, S. (2014) "Germany and the Eurozone crisis: between hegemony and domestic politics". West European Politics, vol. 37, 1244-63.

Coates, D. (2000) Models of Capitalism: Growth and Stagnation in the Modern Era. Cambridge: Polity Press.

Dizard, J. (2015) "The future of Greek financial negotiations is ancient history". Financial Times, 17 de Abril.

Economist (2014) "Germany's flagging economy: Build some bridges and roads, Mrs Merkel. The German government should invest money in infrastructure, not worry about balancing its budget", 18 de Octubre.

Economist (2015) "The force assaulting the Euro: Europe's ageing population poses a long-term threat to monetary union", 6 de Junio.

Eichengreen, B. (2014) "The Eurozone crisis: the theory of optimum currency areas bites back". Notenstein Academy White Paper Series.

Feld, L. P.; Köhler, E. A., y Nientiedt, D. (2015) "Ordoliberalism, pragmatism and the Eurozone crisis: how German tradition shaped economic policy in Europe". CESifo Working Paper No. 5368, Mayo.

Fratscher, M. (2014) Die Deutschland Illusion: Warum wir unsere Wirtschaft überschätzen und Europa brauchen. Munich: Carl Hanser Verlag.

Gapper, J. (2015) "Deutsche Bank is still stuck in the middle of global finance". Financial Times, 7 de Junio.

Germann, J. (2014) "German «grand strategy» and the rise of neoliberalism". International Studies Quarterly, vol. 58, 706-16.

Giavazzi, F. (2015) "Greeks chose poverty, let them have their way". Financial Times, 9 de Junio.

Giles, C. (2015) "How to deal with a problem child like Greece". Financial Times, 19 de Abril.

Grahl, J. (2001) "Globalized finance: the challenge to the Euro". New Left Review, vol. 8, 23-47.

Hall, P. A. (2014) "Varieties of capitalism and the Euro crisis". West European Politics, vol. 37, 1223-1243.

Hall, P.A., y Soskice, D. (2001) Varieties of Capitalism: The Institutional Foundations of Comparative Advantage. Oxford: Oxford University Press.

Harvey, D. (2011) The Enigma of Capital and the Crises of Capitalism. Londres: Profile Books.

Hillebrand, R. (2015) "Germany and its Eurozone crisis policy: the impact of the country's ordoliberal heritage". German Politics and Society, vol. 33, 6-24.

Jacoby, W. (2014) "The politics of the Eurozone crisis: two puzzles behind the German consensus". German Politics and Society, vol. 32, 70-85.

Jessop, B. (2012) "The world market, variegated capitalism, and the crisis of European integration", en P. Nousios et al. (eds.) Globalization and European Inte- 
gration: Critical Approaches to Regional Order and International Relations. Londres: Routledge, 91-111.

Kaelberer, M. (2005) "Deutschmark nationalism and Europeanized identity: exploring identity aspects of Germany's adoption of the Euro". German Politics, vol. 14, 283-96.

Kundnani, H. (2015) The Paradox of German Power. Nueva York: Oxford University Press.

Munchau, W. (2014) "The wacky economics of Germany's parallel universe". Financial Times, 17 de Noviembre.

O'Callaghan, P. (2012) "Collective memory in law and policy: the problem of the sovereign debt crisis". Legal Studies, vol. 32, 642-60.

Piris, J. C. (2011) The Future of Europe: Towards a Two-Speed EU? Cambridge: Cambridge University Press.

Polito, V., y Wickens, M. (2014) "How the Euro crisis evolved and how to avoid another: EMU, fiscal policy and credit ratings". Journal of Macroeconomics, vol. 39, 364-74.

Pritchett, L., y Summers, L. (2014) "Asiaphoria meets regression to the mean". NBER Working Paper 20573. Cambridge (MA): National Bureau of Economic Research.

Ritter, G. A. (2011) The Price of German Unity: Reunification and the Crisis of the Welfare State. Oxford: Oxford University Press.

Segreto, L., y Wubs, B. (2014) "Resistance of the defeated: German and Italian big business and American anti-trust policy, 1945-1957". Enterprise and Society, 15: $307-36$.

Sinn, H-W. (2014) The Euro Trap: On Bursting Bubbles, Budgets, and Beliefs. Oxford: Oxford University Press.

Stark, J. (2015) "The historical and cultural differences that divide Europe's union". Financial Times, 11 de Febrero.

Streeck, W. (2015) "The strikes sweeping Germany are here to stay". Guardian, 22 de Mayo.

Streeck, W., y Yamamura, K. (eds.) (2001) The Origins of Nonliberal Capitalism: Germany and Japan in Comparison. Ithaca (NY): Cornell University Press.

Tooze, A. (2012) "Germany's unsustainable growth: austerity now, stagnation later". Foreign Affairs, vol. 95, September/October, 23-30.

Wagstyl, S. (2015) "Germans' unhealthy obsession with a Greek «Stinkefinger»". Financial Times, 20 de Marzo.

Wagstyl, S., y Vasagar, J. (2015) “Germans' impatience with Merkel on Greece bailout talks grows". Financial Times, 23 de Junio.

Wolf, M. (2015) "Divorce Greece in haste, repent at leisure". Financial Times, 17 de Junio.

Zielonka, J. (2014) Is the EU Doomed? Cambridge: Polity Press. 